\title{
Community Monitoring of Health Parameters in People with Intellectual Disabilities Prescribed Lithium
}

\section{Howkins, J}

http://hdl.handle.net/10026.1/17119

\author{
10.1080/19315864.2021.1892889 \\ Journal of Mental Health Research in Intellectual Disabilities \\ Informa UK Limited
}

All content in PEARL is protected by copyright law. Author manuscripts are made available in accordance with publisher policies. Please cite only the published version using the details provided on the item record or document. In the absence of an open licence (e.g. Creative Commons), permissions for further reuse of content should be sought from the publisher or author. 


\title{
Community Monitoring of Health Parameters in People with Intellectual Disabilities Prescribed Lithium
}

\author{
Joshua Howkins ${ }^{\mathrm{a}}$, Mike Wilcock ${ }^{\mathrm{b}}$, and Rohit Shankar (iD ${ }^{\mathrm{a}, \mathrm{c}}$ \\ aCornwall Intellectual Disability \& Epilepsy Research (CIDER) Centre, Cornwall Partnership NHS \\ Foundation Trust, Truro, UK; ${ }^{\text {b} R o y a l ~ C o r n w a l l ~ H o s p i t a l ~ T r u s t, ~ T r u r o, ~ U K ; ~ ' U n i v e r s i t y ~ o f ~ E x e t e r ~ M e d i c a l ~}$ \\ School, Truro, UK
}

\begin{abstract}
Background: Lithium is well described in managing certain mental illnesses including in people with intellectual disabilities (ID). It requires regular monitoring particularly of serum levels and relevant biochemistry. However, existing monitoring protocols do not provide ID-specific guidance leading to increased risk of poorquality care. This study aims to construct a protocol to aid monitoring in primary care in this cohort. Need for a protocol is further explored by retrospectively auditing monitoring standards in people with ID in Cornwall, UK, and confirming gaps in current practice which may be minimized with clearer guidance.

Methods: Protocol was developed drawing on existing guidance for the general population and considering challenges and best practice associated with monitoring in people with ID. The protocol was applied as an audit to all people with ID currently on lithium on the GP ID register across all GP practices in the county of Cornwall, UK, to explore current standards of monitoring to help elucidate whether increased guidance may be of use.

Results: A novel protocol was developed and supplemented with additional information which is hoped to provide a useful reference guide in primary care. During audit, nine of the ten people with ID receiving prescriptions for lithium across the county were identified and data collected. Audit showed monitoring was to a reasonably high standard, though blood tests and annual health checks were not always performed within preferred maximum timeframes.

Conclusions: This protocol represents the first ID-specific approach for monitoring lithium and associated health parameters in primary care. Auditing against the protocol showed gaps in current standards of care which may indicate a need for clearer published guidance. Some groupings of results highlighted particular areas of need. We hope that clear protocols, such as ours, may aid safe and timely monitoring of lithium treatment in future.
\end{abstract}

\section{KEYWORDS}

Community; monitoring; lithium; intellectual disability

\section{Background}

Lithium is well described in managing certain mental health conditions and effective in treating bipolar disorder and recurrent depression (Abou-Saleh et al., 2017; Severus et al., 2014; Undurraga et al., 2019). In people with ID, it 
may also be used to help manage agitation and aggression (Craft et al., 1987; Worrall et al., 1975).

However, there is concern about the over-use of psychotropic medication in people with ID, both for psychiatric diagnoses and in "off label" prescribing, and the high burden of polypharmacy (Branford et al., 2019; McMahon et al., 2020; Sheehan et al., 2015). In recent years particularly, the UK Government has committed to improving the use of psychotropic medication in people with ID, as encapsulated in the STopping Over Medication of People with a learning disability, autism, or both program (STOMP) (Shankar et al., 2019). Although not included in STOMP, lithium has a well-documented adverse effect profile and narrow therapeutic window and commands a significant burden of monitoring on patients and the healthcare system (National Patient Safety Agency, 2009).

Guidance on prescribing and monitoring lithium in the general population exists both nationally and locally in the UK (Joint Formulary Committee, 2019; Royal Cornwall Hospitals NHS Trust, 2019; SPS et al., 2017; Taylor et al., 2018). However, even with this clear guidance, full monitoring compliance has been found to be substandard (Nederlof et al., 2019). No specific national guidance exists for the ID cohort which may present an additional source of uncertainty around monitoring and increase the risk to patients (De Leon, 2012).

Monitoring of drug treatment is important in this cohort for a number of reasons. People with ID can be more likely to react adversely to medications or at lower doses than the general population (Pary \& Hurley, 2006). This issue is compounded by the higher burden of co-morbidity and polypharmacy often observed (Kinnear et al., 2018), which has been shown to lead to higher rates of premature mortality (Heslop et al., 2014). Adverse effects may be masked or present only through a change in behavior (Pary \& Hurley, 2006; Valdovinos et al., 2005) and people with ID may struggle to seek help for adverse effects due to communication difficulties (Lindsay et al., 2020), an issue compounded by the possibility of diagnostic overshadowing which can delay or undermine proper investigation and management (Lindsay et al., 2020).

Considering lithium specifically, many body systems can be negatively affected, especially with chronic use (Joint Formulary Committee, 2019; Shine et al., 2015; Toxbase, n.d.).

Rapid review of the literature on the use of lithium in people with ID highlights evidence of multi-system adverse effects in a pattern largely homogenous with those experienced by the general population (Canan et al., 2008; El-Bakush et al., 2014; Janowsky et al., 2011, 2009; Pary, 1991; Pirotte et al., 2008; Worrall et al., 1975). Both reversible and irreversible issues were noted though Janowsky et al. in 2009 and 2011 highlight the potential for chronic kidney damage to occur.

In people with ID, lithium toxicity may occur at serum levels considered therapeutic in the general population (Andrade et al., 1988; Maruta, 2003; Otsuka et al., 2012; Soni, 2019). Additionally, there are many examples 
highlighting the disproportionately high burden of polypharmacy in this group (El-Bakush et al., 2014; Hadley et al., 1989; Takahashi et al., 2000; Valdovinos et al., 2005). Together, these add weight to the need to achieve regular monitoring and to reduce over-prescribing, a key tenet of STOMP and current clinical practice.

Behavior change being the sole or primary change noted in a patient experiencing lithium-related adverse effects is evidenced clearly (Hadley \& Cason, 1989; Maruta, 2003; Nishikawa et al., 1992; Takahashi et al., 2000; Valdovinos et al., 2005). The difficulty that clinicians may encounter in assessing and monitoring patients is described in the literature, with evidence presented of methods to increase engagement between healthcare providers and service users to help empower patients and reduce diagnostic overshadowing (Bhaumik et al., 2007; Buckley \& Sharrard, 2003; Clarke \& Pickles, 1994; ; Pary \& Hurley, 2006; Paton et al., 2011).

Significant potential for uncertainty, overshadow and subsequent harm is evident from the above. Therefore, we suggest that bespoke and clear guidance on monitoring is vital to aid primary care physicians in prescribing safely, and to patients in allowing full consideration of treatment options.

Due to this need and the current gap in guidance for the explicit health needs of people with ID, this paper aims to develop and pilot an ID-specific protocol for the monitoring of lithium and associated health parameters in primary practice. Pilot will take the form of a small audit of our service area to assess feasibility.

\section{Methods And Materials}

Relevant national and local guidance on lithium prescribing was sourced in November 2019 (Joint Formulary Committee, 2019; National Collaborating Centre for Mental Health, 2014, ; Royal Cornwall Hospitals NHS Trust, 2019; SPS et al., 2017; Taylor et al., 2018) to provide a base upon which to structure our novel ID-specific protocol. These guidelines are listed in (Table 1) along with extracted key points for monitoring.

Our protocol (Figure 1) was brought together through discussion of this selected literature review amongst our panel of psychiatrists and pharmacists, assessing the evidence base for alterations or additions to the monitoring requirements for the general population. The summary of evidence used for the protocol formation is presented in (Table 2).

The devised protocol (Figure 1) formed the basis for a countywide pilot audit into the monitoring of lithium treatment and associated health parameters in people with ID in the county of Cornwall, UK (pop:538,000).

The core monitoring parameters utilized for the audit were serum lithium levels and other key blood tests (full blood count, electrolytes 
Table 1. Key sources for national guidance on prescribing and monitoring lithium.

\begin{tabular}{lc}
\hline Source & Summary of monitoring requirements \\
\hline BNF (Joint Formulary Committee, 2019) & Pre-treatment: BMl; cardiac; electrolytes; FBC; renal; \\
& thyroid. ECG if risk factors. \\
& During treatment: BMl; electrolytes; eGFR; plasma \\
& levels; thyroid function. \\
Maudsley prescribing guidelines (Taylor et al., 2018) & Pre-treatment: BMl; cardiac function; renal; thyroid. \\
& ECG if risk factors. \\
& During treatment: eGFR; plasma levels; thyroid \\
& function. \\
SPS guide for monitoring in primary care (SPS et al., & Pre-treatment: BMl; electrolytes; FBC; renal; thyroid. \\
2017) & ECG if risk factors. \\
& During treatment: annual health review (including \\
& blood pressure); BMl; plasma levels; thyroid. \\
NICE guidelines for bipolar disorder (National & Pre-treatment: BMl; calcium; electrolytes; eGFR; FBC, \\
Collaborating Centre for Mental Health, 2014) & thyroid. ECG if risk factors. \\
& During treatment: BMl; calcium; plasma levels; renal; \\
NICE guidelines for depression (National Collaborating & thyroid function. \\
Centre for Mental Health, 2010) & During treatment: plasma levels; renal; thyroid \\
& function. ECG if risk factors. \\
\hline
\end{tabular}

Abbreviations: BMI (basal metabolic index); ECG (electrocardiogram); eGFR (estimated glomerular filtration rate); FBC (full blood count).

and kidney function, thyroid function, and calcium) within the previous 6 months and annual health check within the previous 12 months. Audit registered with Cornwall Foundation NHS Trust clinical audit department reference 619;02/2020, results displayed in (Table 3).

Anonymized patient data were gathered by first searching ECLIPSE LIVE (which securely accesses patient data from general practice (GP) computer systems, in a non-identifiable report) to facilitate identification of practices with patients meeting our criteria (current lithium prescription in any form and diagnosis of learning disability, intellectual disability, or unspecified disorder of scholastic skills). Individual practices where the persons were identified were then contacted. Data was requested and audited only for the key monitoring factor timeframes (blood tests six months and AHC twelve months as above) in people matching the specified cohort to preserve anonymity. Audit results were noted in tabular format as either success or failure based on the criteria being met and within the expected specified timeframe (Table 3).

\section{Results}

\section{Construction of the Protocol}

In devising the ID-specific monitoring protocol (Figure 1), we considered the evidence as described in the introduction for implications on the regimen for monitoring health parameters, above guidance for the general population (Table 1). For comparison, key features of this guidance are (when amalgamated): weekly lithium levels on initiation and with dose adjustments until stable, trending 


\section{Monitoring protocol for lithium and associated health parameters in people with}

\begin{tabular}{|c|}
\hline Baseline \\
FBC \\
U\&E including eGFR \\
Calcium level \\
TFT \\
BMI \\
\hline
\end{tabular}

\begin{tabular}{|c|c|}
\cline { 2 - 3 } ECG if cardia & $\begin{array}{c}\text { Monitoring } \\
\text { 3-monthly for first year } \\
\text { FBC } \\
\text { U\&E including eGFR } \\
\text { TFT } \\
\text { 6-monthly (continuing) } \\
\text { FBC } \\
\text { U\&E including eGFR } \\
\text { TFT } \\
\text { Calcium levels } \\
\text { Annually (continuing) } \\
\text { Health check }\end{array}$ \\
\hline
\end{tabular}

\section{$\underline{\text { intellectual disabilities }}$}

Lithium levels
Target range $0.6-0.75 \mathrm{mmol} / \mathrm{L}$
Therapeutic window $0.4-1.0 \mathrm{mmol} / \mathrm{L}$
Take trough levels at $12 \mathrm{hours}$
Monitoring
Weekly serum level until stable
Then 3-monthly
6-monthly if chronically stable
Stopping treatment
Do not discontinue abruptly
Titrate down over 4-12 weeks

\section{Additional advice}

Assess acute physical and behavioural changes in person.

Consider whether lithium may be causative or if change may alter pharmacokinetics, necessitating closer monitoring All patients should receive a purple lithium book

Avoid significant changes to sodium intake and fluid balance

Be aware of interacting medications

Pregnancy avoidance and effective contraception

Missed dose: take up until 3 hours after usual time

Always consider patient's mental capacity to provide informed consent to all processes and if lacking formal best interest processes

\begin{tabular}{|c|c|}
\hline Signs of toxicity & $\begin{array}{l}\text { Mild: GI upset; tremor; lethargy; lightheadedness } \\
\text { Moderate: confusion and agitation; tachycardia; hypertonia } \\
\text { Severe: seizure; cardiac dysrhythmia; cerebellar signs }\end{array}$ \\
\hline \multicolumn{2}{|c|}{$\begin{array}{l}\text { Abbreviations: BMI (basal metabolic index); eGFR (estimated glomerular filtration rate } \\
\text { FBC (full blood count); TFT (thyroid function test); U\&E (urea and electrolytes) }\end{array}$} \\
\hline
\end{tabular}

Figure 1. Proposed standard for monitoring with additional educational information contained for healthcare worker and patient benefit.

to 6-monthly once chronically stable; baseline full blood count, calcium, renal function, thyroid function and BMI; and 3-monthly calcium, renal function and thyroid function, trending to 6-monthly for long-term monitoring, with increased regularity if concern. 
Table 2. Summary of evidence used in formation of protocol (Figure 1).

\begin{tabular}{|c|c|c|}
\hline Source & Summary of key information & Section of protocol informed \\
\hline $\begin{array}{l}\text { Andrade et al. } \\
\text { (1988) } \\
\text { Case report }\end{array}$ & $\begin{array}{l}\text { Neurotoxicity developed at plasma levels } \\
\text { considered normal for general population. } \\
\text { Hypothesis presented that the subject's } \\
\text { intellectual disability was a predisposing } \\
\text { factor for this. }\end{array}$ & $\begin{array}{l}\text { Initiation of treatment and serum lithium } \\
\text { levels. } \\
\text { No change made to protocol as current best } \\
\text { guidance is the target range specified. In } \\
\text { the UK, lithium is only initiated under } \\
\text { specialist supervision and all individuals } \\
\text { should be closely monitored during periods } \\
\text { of dose adjustment. }\end{array}$ \\
\hline $\begin{array}{l}\text { Canan et al. } \\
\text { (2008) }\end{array}$ & $\begin{array}{l}\text { Initiation of lithium therapy unmasked } \\
\text { previously unknown cardiac abnormality } \\
\text { resulting in arrhythmia which disappeared } \\
\text { after discontinuation and dialysis. }\end{array}$ & $\begin{array}{l}\text { No change to protocol as, although } \\
\text { population may be at increased risk of } \\
\text { cardiac abnormality, common accessible } \\
\text { investigations were not felt to be sensitive } \\
\text { enough for screening purposes. }\end{array}$ \\
\hline $\begin{array}{l}\text { El-Bakush et al. } \\
\text { (2014) } \\
\text { Case report }\end{array}$ & $\begin{array}{l}\text { Missed diagnosis for two weeks of lithium } \\
\text { toxicity following dose increase resulting } \\
\text { significant morbidity. }\end{array}$ & $\begin{array}{l}\text { Lithium plasma level schedule (weekly until } \\
\text { stable). }\end{array}$ \\
\hline $\begin{array}{l}\text { Hadley et al. } \\
\text { (1989) } \\
\text { Case report }\end{array}$ & $\begin{array}{l}\text { Burden of polypharmacy: addition of } \\
\text { fluoxetine to otherwise established lithium } \\
\text { therapy resulted in lithium toxicity and } \\
\text { mania. }\end{array}$ & $\begin{array}{l}\text { Additional advice section. } \\
\text { Lithium's propensity to interact with other } \\
\text { medications is well known and a list would } \\
\text { not be exhaustive. }\end{array}$ \\
\hline $\begin{array}{l}\text { Janowsky et al. } \\
\text { (2009) } \\
\text { Retrospective } \\
\text { case-control }\end{array}$ & $\begin{array}{l}\text { Lithium shown as an independent risk factor } \\
\text { for renal failure. }\end{array}$ & $\begin{array}{l}\text { 6-monthly renal function testing. } \\
\text { Although renal function did not return to } \\
\text { normal levels on treatment cessation, the } \\
\text { insidious nature of lithium-related renal } \\
\text { failure was felt to be covered by current } \\
\text { 6-monthly guidance. }\end{array}$ \\
\hline $\begin{array}{l}\text { Janowsky et al. } \\
\text { (2011) } \\
\text { Retrospective } \\
\text { case-control }\end{array}$ & $\begin{array}{l}\text { Long term lithium use is a risk factor for } \\
\text { chronic renal insufficiency. No recovery in } \\
\text { baseline eGFR after cessation of lithium }\end{array}$ & $\begin{array}{l}\text { 6-monthly renal function testing. } \\
\text { As above. }\end{array}$ \\
\hline $\begin{array}{l}\text { Maruta (2003) } \\
\text { Case report }\end{array}$ & $\begin{array}{l}\text { Missed diagnosis and late presentation of } \\
\text { lithium toxicity in patient presenting with } \\
\text { weight loss. }\end{array}$ & Annual health check; BMI. \\
\hline $\begin{array}{l}\text { Nishikawa et al. } \\
\text { (1992) } \\
\text { Case report }\end{array}$ & $\begin{array}{l}\text { Lithium use, particularly in combination with } \\
\text { other psychotropics, leading to diabetes } \\
\text { insipidus characterized by compulsive } \\
\text { drinking. }\end{array}$ & $\begin{array}{l}\text { Not explicitly stated in protocol; discussed in } \\
\text { paper as covered by clinical responsibility } \\
\text { to investigate acute behavioral changes. }\end{array}$ \\
\hline $\begin{array}{l}\text { Otsuka et al. } \\
\text { (2012) } \\
\text { Case report }\end{array}$ & $\begin{array}{l}\text { Unusual presentation of nephrogenic diabetes } \\
\text { insipidus as a result of chronic lithium use. } \\
\text { Polydipsia only noted through change in } \\
\text { behavior: client seen to be drinking from } \\
\text { faucet. }\end{array}$ & As above. \\
\hline $\begin{array}{l}\text { Pary et al. (1991) } \\
\quad \text { Cohort }\end{array}$ & $\begin{array}{l}\text { Assessment of adverse effect profile in lithium } \\
\text { use. } 58 \text { week follow up revealed } 67 \% \text { of } \\
\text { subjects reporting adverse effects. }\end{array}$ & As above. \\
\hline $\begin{array}{l}\text { Pary et al. (2006) } \\
\text { Qualitative, } \\
\text { mixed }\end{array}$ & $\begin{array}{l}\text { Discussed challenges in recognition of } \\
\text { psychotropic medication adverse effects in } \\
\text { this cohort. }\end{array}$ & As above. \\
\hline $\begin{array}{l}\text { Pirotte et al. } \\
\text { (2008) } \\
\text { Case report }\end{array}$ & $\begin{array}{l}\text { Lithium unmasking cardiac abnormality in } \\
\text { individual with no previous abnormal } \\
\text { cardiac history. }\end{array}$ & $\begin{array}{l}\text { Pre-treatment investigations would have been } \\
\text { unlikely to prevent this } \\
\text { so no additions made to protocol as per } \\
\text { Pirotte et al.: "certain drugs or medical } \\
\text { conditions can unmask the Brugada } \\
\text { syndrome in a patient with previously } \\
\text { normal ECGs and no cardiac history" } \\
\text { Also see entry for Canan et al. (2008). }\end{array}$ \\
\hline $\begin{array}{l}\text { Soni }(2018) \\
\quad \text { Case report }\end{array}$ & $\begin{array}{l}\text { Unusual presentation of neurotoxicity } \\
\text { secondary to lithium use, with therapeutic } \\
\text { serum levels. Misdiagnosed as dementia for } \\
18 \text { months }\end{array}$ & $\begin{array}{l}\text { Serum lithium level frequency and } \\
\text { presumption of ad hoc clinical investigation } \\
\text { due to change in behavior. }\end{array}$ \\
\hline
\end{tabular}


Table 2. (Continued).

\begin{tabular}{|c|c|c|}
\hline Source & Summary of key information & Section of protocol informed \\
\hline $\begin{array}{l}\text { Takahashi et al. } \\
\text { (2000) } \\
\text { Case report }\end{array}$ & $\begin{array}{l}\text { Co-administration of levofloxacin resulting in } \\
\text { lithium toxicity in previously established } \\
\text { therapy. }\end{array}$ & $\begin{array}{l}\text { Additional advice section. } \\
\text { As per Hadley et al. (1989). }\end{array}$ \\
\hline $\begin{array}{l}\text { Worrall et al. } \\
\text { (1975) } \\
\text { Randomized } \\
\text { controlled trial }\end{array}$ & $\begin{array}{l}\text { High incidence ( } 25 \%) \text { of neurotoxicity in small } \\
\text { RCT of lithium for symptoms of aggression. }\end{array}$ & $\begin{array}{l}\text { Serum lithium level frequency. } \\
\text { Also felt clinically captured due to UK policy } \\
\text { of lithium only being commenced under } \\
\text { specialist supervision. }\end{array}$ \\
\hline $\begin{array}{l}\text { Valdovinos et al. } \\
\text { (2005) } \\
\text { Retrospective, } \\
\text { qualitative }\end{array}$ & $\begin{array}{l}\text { Assessed range of reported adverse effects. } \\
\text { Noted difficulty in discriminating between } \\
\text { change in behavior due to mood } \\
\text { fluctuation or medication adverse effect. }\end{array}$ & As per Nishikawa et al. (1992). \\
\hline
\end{tabular}

Sources in Table 1 were pivotal in providing information for all parts of the protocol. The following sources provided evidence which supplemented this, allowing consideration of changes specific to needs of the ID population.

Table 3. Results of audit against concordance with monitoring protocol for nine patients (one per row) " $\square$ " indicates patient found to have testing within pre-defined timeframe whilst " $\mathrm{X}$ " indicates absence.

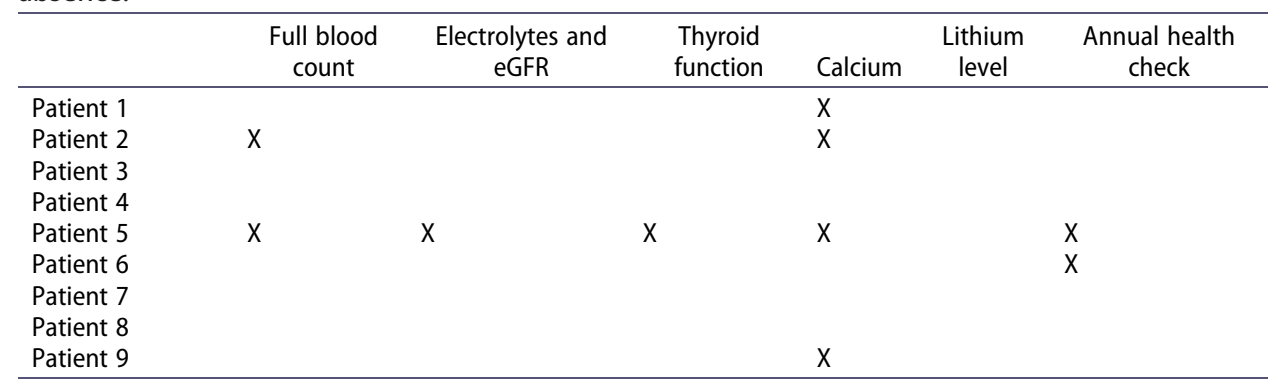

Considering lithium level monitoring, it was felt that general guidance should suffice for safe monitoring in our population, if properly adhered to. There is no conceivable need for monitoring more than once weekly outside of the emergency inpatient setting. Therefore, guidance was maintained at weekly until stable, trending through 3-monthly to 6-monthly when the clinician is satisfied of chronic stability. Frequency should increase in times of clinical concern or physiological change, trending back through the above pattern as the situation settles.

Considering the other health parameters, baseline blood test investigations overall were proposed to remain the same. Prescription of lithium is generally reserved for those in good or at least stable health. Patients with significant comorbidities should be reviewed on an individual basis for suitability of treatment and these cases cannot be covered by the scope of a generalized monitoring protocol. Regular serum monitoring three monthly trending toward six monthly, with evidence of stability remains safe and practical, if adhered to. Inherent within this recommendation is the provision that clinicians should increase monitoring in the acute setting as guided by the clinical picture.

Key to this decision is that monitoring frequency must strike a balance between patient acceptability, healthcare capacity and clinical necessity. It is 
not practical for guidance to demand overly frequent monitoring, and a balance must be struck. Evidence for system-specific adverse effects is already well documented and tends to present over mid- to long-term rather than immediately. Therefore, it was felt to be of no clinical benefit to suggest increasing the standard monitoring frequency of the serum markers as already defined for the general population. Disruption to normal physiological processes and parameters due to acute illness or injury is a different matter and, once again, we expect the clinician to utilize clinical judgment when considering investigations in the acute setting.

The diverse nature in which adverse effects may present in our population, and the noted potential difficulties in expressing these, was felt to represent a requirement for particularly close care, distinct from patient needs in the general population. On discussion, it was felt that if concerns were raised in the community of an acute physical or behavioral change, a healthcare professional would be expected to rapidly assess the concerned person. Many areas have ID-specific services in addition to GPs, family doctors and hospital emergency departments. Therefore, acute change is more likely to be assessed as part of standard care than it might be for the general population. Reminder of the increased need of in-person assessment of acute changes when a patient is prescribed lithium was inserted into the protocol as a result of this discussion. Due to this enhanced ad hoc clinical assessment, it was not recommended to increase the advice for formal, regular biochemical monitoring in the protocol, with it felt preferably performed on an individualized basis in order to limit the burden of monitoring on stable patients.

All people with ID in the UK should receive an annual health check (AHC). This broad assessment covers many of the wider issues that are of particular importance in lithium treatment including medication reviews, weight and baseline physical observations and behavior and mental health review. Therefore, attendance of this review is vital to the ongoing assessment and optimization of health, and of the ongoing assessment of suitability for lithium treatment.

Note was made of the support in the evidence and anecdotally for increased patient and carer empowerment and for more structural guidance for GPs. In the advice box it has been made explicit to ensure mental capacity for informed consent for various decisions especially interventional ones given the cognitive and communicative vulnerabilities of people with ID. Where there is a lack of mental capacity identifed as per the Mental Capacity Act 2005 UK or similar guidance due best interest process needs following. This protocol is hoped to go some way toward providing that support by supplying clear guidance to follow. Due to this, additional information was inserted onto the monitoring sheet in boxes so that the protocol could also be used to clarify advice and requirements as necessary, providing a reference frame for clinical review above its baseline role as a protocol for monitoring. 


\section{Audit Results}

The pilot audit identified ten people with ID prescribed lithium in Cornwall. Of these ten people, full required data on monitoring was accessed for nine (Table 3). The tenth person was unable to be uncovered in GP records. It is unclear whether this was due to improper coding, unknown variations in coding between systems or inadequate information being provided due to the anonymized nature of the data.

All patients had received serum monitoring of lithium levels within the timeframe recommended by protocol for long term management (6 months). Most other serum markers were similarly well accounted for, though trends were offset by patient 5 having not received testing for any markers other than lithium level. Aside from results pertaining to patient 5, serum markers were obtained within the 6-month timeframe for all markers other than full blood count in one patient (patient 2), and calcium markers in 3 patients (patients 1 , 2 and 9). Annual health check was performed within the past year in all patients other than patients 5 and 6 .

\section{Discussion}

\section{Discussion of the Protocol}

We were satisfied with the final protocol, believing it covers relevant markers and provides a safe yet practical guidance for monitoring in the stable setting. We hope that the supplementary boxes "additional advice" and "signs of toxicity" complement the protocol to allow a reference for primary care of additional factors that must be remembered when responsible for lithium prescriptions in people with ID.

\section{Discussion of Pilot Audit Results}

Audit highlighted some notable trends in the current monitoring of lithium in people with ID in the community (Table 3), which we believe highlight the requirement for a protocol such as this.

Calcium testing is the most frequently neglected (for four out of nine patients within our 6-month timeframe). It is felt that this is potentially due to the wording of current national advice from the British National Formulary (Joint Formulary Committee, 2019). Calcium is grouped with "electrolytes" in documentation but not practically recognized as such: most UK biochemistry ordering systems have separate order sets for "urea and electrolytes" (including sodium, potassium, urea and creatinine only) and for calcium (or sometimes "bone profile"). Inconsistencies such as this are potentially a source of shortcoming which should be resolved by having one clear monitoring protocol available. 
Lack of AHC completion is a source of concern. Every person with ID should have a regular, yearly AHC in addition to any suitable acute physical health monitoring including, where appropriate, relevant biochemistry. This is of particular importance in the setting of chronic physical conditions and long-term psychotropic medication use. It is of highlighted importance by the Learning Disability Mortality Review (LeDeR) program and leads to a proven reduction in mortality (Heslop et al., 2014; Kennedy et al., 2019).

A further notable concern is of the one participant in the audit having refused all monitoring interventions other than plasma lithium level in the past year, implying that blood was taken but that either other investigations were refused by the patient or not requested by the GP. If a patient cannot be relied upon to fulfil the requirements of safe practice, it should be assessed whether lithium is suitable for them or whether an alternative is preferable. Capacity to consent to treatment is not a static concept and should be reviewed if a patient (and if appropriate their next of kin or legal appointee) is unwilling or unable to fulfil the requirements for safe treatment or if attendance at monitoring reviews lapses over time. If this lapse in monitoring is instead due to a lack of awareness by the GP, again is it hoped that provision of a clear monitoring protocol may improve concordance to safe monitoring practice.

\section{Limitations of the Paper}

Taken together, the additional value of this revised protocol cannot be fully supported by the evidence provided in this manuscript; for that a direct comparison of old and new protocols in a larger sample size would be required. Whilst the rapid literature review allowed informed deliberation on modifications to monitoring guidance for the general population, the protocol cannot be taken as drawing fully from all possible evidence as a systematic review of the literature did not take place. English language only and limited databases were searched and thus the provision of evidence to the panel suffers from an amount of structural bias. In addition to this, sources of evidence were not individually appraised or critiqued, meaning that information drawn from them cannot be relied upon as high quality. Withstanding these potential biases, the regimen recommended by our IDspecific protocol does not vary substantially from that for the general population. The only additional factors are reminders to complete the annual health check, as already nationally recommended, and advice on common side effects and signs of toxicity, though these are not specific to the ID population. Therefore, we propose that whilst a systematic review would provide higher quality evidence, our protocol provides a practical, timely and useful guide and aide memoire for clinical practice.

We feel the protocol well balances the need for accurate and consistent monitoring with burden on clients and the healthcare system, though opinions 
on where this balance should properly sit may vary between observers. The protocol structure is reliant upon appropriate healthcare workers assessing acute changes in health and behavior of patients and conducting necessary investigations in addition to those laid out. This goes without saying as a core tenet of clinical practice, though remains vital within the provision of healthcare to people with ID.

In considering only one geographical area our pilot audit was limited by small sample size. As only one method of extracting data was used, we were reliant upon access and correct recording of test results on GP systems. Further, the audit was retrospective in nature of examining data. However, when considered purely within the confines of assessing whether all health parameters are currently being monitored, and therefore providing evidence for whether clearer protocols may improve monitoring standards, we propose that our small audit is suitable to answer this question. Next steps could be development of this project into a quality improvement initiative encompassing obtaining physician feedback on the protocol, considering if more guidance/training is needed for the additional advice, e.g., assessing acute changes.

\section{Conclusions}

Our protocol represents the first standardized, personalized approach for monitoring lithium and associated health parameters in people with ID. The protocol captures key needs of people in this cohort as established by rapid literature review and expert discussion. This audit is possibly the first review of such health parameters within this population in a systematic way.

Application of the audit highlighted that the population examined had most essential tests within the required timeframe. Some groupings of results point toward a lack of understanding around monitoring. Our protocol should help clarify and improve this if incorporated systematically. Results may be mirrored in other service areas; further audits would reveal this and may highlight a need for centralized improvement of service in this area and therefore a national requirement for a protocol such as ours to guide clinical practice.

This audit gives proof of concept of a need for improved formalized guidance for monitoring of lithium prescribing in the community, which we believe our protocol provides. It has identified a gap in the STOMP program which has not included lithium within its ambit.

\section{Disclosure Statement}

$\mathrm{JH}$ and MW report no conflicts. RS has received institutional and research support from LivaNova, GW pharma, UCB, Eisai, Special Products, Averelle and Desitin outside the submitted work. 


\section{Funding}

This research did not receive any specific grant from funding agencies in the public, commercial, or not-for-profit sectors.

\section{ORCID}

Rohit Shankar (D) http://orcid.org/0000-0002-1183-6933

\section{References}

Abou-Saleh, M. T., Müller-Oerlinghausen, B., \& Coppen, A. J. (2017). Lithium in the episode and suicide prophylaxis and in augmenting strategies in patients with unipolar depression. International Journal of Bipolar Disorders, 5(1), 11. https://doi.org/10.1186/s40345-0170080-x

Andrade, C., Gangadhar, B. N., \& Channabasavanna, S. M. (1988). Lithium-induced paradoxical neurotoxicity-a risk factor. Indian Journal of Psychiatry, 30(2), 201.

Bhaumik, S., Watson, J. M., Falconer Smith, J. F., Nadkarni, S., Biswas, A., \& Gangadharan, S. K. (2007). A lithium register for adults with intellectual disabilities-Can it work? The British Journal of Development Disabilities, 53(104), 37-45. https://doi.org/10. 1179/096979507799103496

Branford, D., Gerrard, D., Saleem, N., Shaw, C., \& Webster, A. (2019). Stopping overmedication of people with intellectual disability, autism or both (STOMP) in England part 1-history and background of STOMP. Advances in Mental Health and Intellectual Disabilities.

Buckley, C., \& Sharrard, H. (2003). Lithium monitoring for patients with learning disability: The role of the general practitioner. Quality in Primary Care, 11(4), 329-331.

Canan, F., Kaya, A., Bulur, S., Albayrak, E. S., Ordu, S., \& Ataoglu, A. (2008). Lithium intoxication related multiple temporary ecg changes: A case report. Cases Journal, 1(1), 1-4. https://doi.org/10.1186/1757-1626-1-156

Clarke, D. J., \& Pickles, K. J. (1994). Lithium treatment for people with learning disability: Patients 'and carers' knowledge of hazards and attitudes to treatment. Journal of Intellectual Disability Research, 38(2), 187-194. https://doi.org/10.1111/j.1365-2788.1994.tb00373.x

Craft, M., Ismail, I. A., Krishnamurti, D., Mathews, J., Regan, A., Seth, R. V., \& North, P. M. (1987). Lithium in the treatment of aggression in mentally handicapped patients: A double-blind trial. The British Journal of Psychiatry, 150(5), 685-689. https://doi.org/10. 1192/bjp.150.5.685

$\lambda$

El-Bakush, A., Fuller, A., Tello, W., \& Nugent, K. (2014). Diverse complications in a patient with lithium toxicity. Journal of Investigative Medicine, 62(2), 430-430.

Hadley, A., \& Cason, M. P. (1989). Mania resulting from lithium-fluoxetine combination. The American Journal of Psychiatry., 146(12), 1637-1638.

Heslop, P., Blair, P. S., Fleming, P., Hoghton, M., Marriott, A., \& Russ, L. (2014). The confidential inquiry into premature deaths of people with intellectual disabilities in the UK: A population-based study. The Lancet, 383(9920), 889-895. https://doi.org/10.1016/ S0140-6736(13)62026-7

Janowsky, D. S., Buneviciute, J., Hu, Q., \& Davis, J. M. (2011). Lithium-induced renal insufficiency: A longitudinal study of creatinine increases in intellectually disabled adults. 
Journal of Clinical Psychopharmacology, 31(6), 769-773. https://doi.org/10.1097/JCP. 0b013e31823607db

Janowsky, D. S., Soares, J., Hatch, J. P., Zunta-Soares, G., Hu, Q., \& Davis, J. M. (2009). Lithium effect on renal glomerular function in individuals with intellectual disability. Journal of Clinical Psychopharmacology, 29(3), 296-299. https://doi.org/10.1097/JCP. 0b013e3181a5dcb7

Joint Formulary Committee. (2019). BNF 77: March 2019. Pharmaceutical Press.

Kennedy, N., Brophy, S., Kennedy, J., \& Kerr, M. (2019). Mortality in adults with learning disabilities with and without a health check: A cohort study. The Lancet, 394, S27. https:// doi.org/10.1016/S0140-6736(19)32824-7

Kinnear, D., Morrison, J., Allan, L., Henderson, A., Smiley, E., \& Cooper, S. A. (2018). Prevalence of physical conditions and multimorbidity in a cohort of adults with intellectual disabilities with and without Down syndrome: Cross-sectional study. BMJ Open, 8(2), e018292. https://doi.org/10.1136/bmjopen-2017-018292

Lindsay, W. R., Chester, V., \& Alexander, R. (2020). The assessment and treatment of personality disorders in people with intellectual and developmental disabilities. In Oxford textbook of the psychiatry of intellectual disability (pp. 141).

Maruta, K. (2003). Lithium intoxication in a patient with severe motor and intellectual disabilities. Brain and Development, 35(5), 422-425.

McMahon, M., Hatton, C., \& Bowring, D. (2020). Polypharmacy and psychotropic polypharmacy in adults with intellectual disability: A cross-sectional total population study. Journal of Intellectual Disability Research, 64(11), 834-851. Advance online publication. https://doi. org/10.1111/jir.12775

National Collaborating Centre for Mental Health. (2010). Depression: The treatment and management of depression in adults (updated ed.). British Psychological Society.

National Collaborating Centre for Mental Health. (2014). Bipolar disorder: The NICE guideline on the assessment and management of bipolar disorder in adults, children and young people in primary and secondary care.

National Patient Safety Agency. (2009). Patient Safety Alert NPSA 2009/PSA005. Safer lithium therapy. Supporting information. Retrieved September 9, 2020, from https://www.sps.nhs. uk/wp-content/uploads/2018/02/2009-NRLS-0921-Safer-lithium-tmation-2010.01.12-v1. pdf

Nederlof, M., Egberts, T. C., van Londen, L., de Rotte, M. C., Souverein, P. C., Herings, R. M., \& Heerdink, E. R. (2019). Compliance with the guidelines for laboratory monitoring of patients treated with lithium: A retrospective follow-up study among ambulatory patients in the Netherlands. Bipolar Disorders, 21(5), 419-427. https://doi.org/10.1111/bdi.12730

Nishikawa, T., Tsuda, A., Tanaka, M., Nishikawa, M., Koga, I., \& Uchida, Y. (1992). Evidence for a direct adverse reaction of neuroleptics in self-induced water intoxication of psychiatric patients. The Kurume Medical Journal, 38(4), 307-310. https://doi.org/10.2739/kurume medj.38.307

Otsuka, R., Rahgoshay, S., \& Caprio, T. (2012). A12: Case of nephrogenic diabetes insipidus due to chronic Lithium use. Journal of the American Geriatrics Society, 60.

Pary, R. (1991). Side effects during lithium treatment for psychiatric disorders in adults with mental retardation. American Journal on Mental Retardation, 96(3), 269-273.

Pary, R. J., \& Hurley, A. D. (2006). Monitoring side-effects to psychiatric medicines in patients with intellectual disability. Mental Health Aspects of Developmental Disabilities, 9(4), 128.

Paton, C., Flynn, A., Shingleton-Smith, A., McIntyre, S., Bhaumik, S., Rasmussen, J., Hardy, S., \& Barnes, T. (2011). Nature and quality of antipsychotic prescribing practice in UK psychiatry of intellectual disability services. Journal of Intellectual Disability Research, 55 (7), 665-674. https://doi.org/10.1111/j.1365-2788.2011.01421.x 
Pirotte, M. J., Mueller, J. G., \& Poprawski, T. (2008). A case report of Brugada-type electrocardiographic changes in a patient taking lithium. The American Journal of Emergency Medicine, 26(1), 113-e1. https://doi.org/10.1016/j.ajem.2007.06.028

Royal Cornwall Hospitals NHS Trust. (2019). Lithium shared care guideline V4.0. Retrieved September 7, 2020, from https://doclibrary-rcht.cornwall.nhs.uk/ RoyalCornwallHospitalsTrust/Internet/DocumentsLibrary/DocumentBrowser/FolderView. aspx?cID=8947

Severus, E., Taylor, M. J., Sauer, C., Pfennig, A., Ritter, P., Bauer, M., \& Geddes, J. R. (2014). Lithium for prevention of mood episodes in bipolar disorders: Systematic review and meta-analysis. International Journal of Bipolar Disorders, 2(1), 15. https://doi.org/10.1186/ s40345-014-0015-8

Shankar, R., Wilcock, M., Oak, K., McGowan, P., \& Sheehan, R. (2019). Stopping, rationalising or optimising antipsychotic drug treatment in people with intellectual disability and/or autism. Drug and Therapeutics Bulletin, 57(1), 10-13. https://doi.org/10.1136/dtb.2018. 000009

Sheehan, R., Hassiotis, A., Walters, K., Osborn, D., Strydom, A., \& Horsfall, L. (2015). Mental illness, challenging behaviour, and psychotropic drug prescribing in people with intellectual disability: UK population based cohort study. BMJ, 351, h4326. https://doi.org/10.1136/bmj. h4326

Shine, B., McKnight, R. F., Leaver, L., \& Geddes, J. R. (2015). Long-term effects of lithium on renal, thyroid, and parathyroid function: A retrospective analysis of laboratory data. The Lancet, 386(9992), 461-468. https://doi.org/10.1016/S0140-6736(14)61842-0

Soni, S. (2019). Lithium neurotoxicity presenting as dementia with therapeutic serum lithium levels. BMJ Case Reports $C P, 12(1)$.

SPS, UKMi, \& NHS. (2017) . A collaboration between London \& South East Medicines Information Service, South West Medicine Information Service and Croydon Clinical Commissioning Group. Suggestions for Drug Monitoring in Adults in Primary Care.

Takahashi, H., Higuchi, H., \& Shimizu, T. (2000). Severe lithium toxicity induced by combined levofloxacin administration. The Journal of Clinical Psychiatry, 61(12), 949. https://doi.org/ 10.4088/JCP.v61n1210d

Taylor, D. M., Barnes, T. R., \& Young, A. H. (2018). The Maudsley prescribing guidelines in psychiatry. John Wiley \& Sons.

Toxbase. (n.d.). Retrieved December 15, 2019, from https://www.toxbase.org/Poisons-Index -A-Z/L-Products/Lithium/

Undurraga, J., Sim, K., Tondo, L., Gorodischer, A., Azua, E., Tay, K. H., Tan, D., \& Baldessarini, R. J. (2019). Lithium treatment for unipolar major depressive disorder: Systematic review. Journal of Psychopharmacology, 33(2), 167-176. https://doi.org/10. $1177 / 0269881118822161$

Valdovinos, M. G., Caruso, M., Roberts, C., Kim, G., \& Kennedy, C. H. (2005). Medical and behavioral symptoms as potential medication side effects in adults with developmental disabilities. American Journal on Mental Retardation, 110(3), 164-170. https://doi.org/10. 1352/0895-8017(2005)110<164:MABSAP >2.0.CO;2

Worrall, E. P., Moody, J. P., \& Naylor, G. J. (1975). Lithium in non-manic-depressives: Antiaggressive effect and red blood cell lithium values. The British Journal of Psychiatry, 126(5), 464-468. https://doi.org/10.1192/bjp.126.5.464 
J. HOWKINS ET AL. 
J. HOWKINS ET AL. 
J. HOWKINS ET AL. 
J. HOWKINS ET AL. 
J. HOWKINS ET AL. 
$26-3$ J. Howkins Et AL. 
J. HOWKINS ET AL. 
J. HOWKINS ET AL. 
$32 \rightarrow$ J. HOWKINS ET AL. 
J. HOWKINS ET AL. 
J. HOWKINS ET AL. 
J. HOWKINS ET AL. 
